\title{
CARACTERIZAÇÃO PLUVIOMÉTRICA DA BACIA HIDROGRÁFICA DO RIO DOCE - RN/BRASIL
}

\author{
COSTA, Franklin Roberto da - franklincosta@uern.br \\ Universidade do Estado do Rio Grande do Norte / UERN
}

\author{
SOUZA, Raquel Franco de - francodesouza.raquel@gmail.com \\ Universidade Federal do Rio Grande do Norte / UFRN
}
SILVA, Sebastião Milton Pinheiro da - sebastiaomilton@gmail.com
Universidade Federal do Rio Grande do Norte / UFRN

\begin{abstract}
RESUMO: A bacia hidrográfica do Rio Doce - RN/Brasil (BHRD-RN) se caracteriza como uma área de atividades agropecuárias, extração mineral e expansão urbana. O objetivo desse estudo foi investigar e espacializar os dados de precipitação da BHRD-RN entre os anos de 1997 e 2016, e realizar uma análise comparativa com dados trabalhados por Castro (2000). Os dados de precipitação foram obtidos na Empresa de Pesquisa Agropecuária do Rio Grande do Norte - EMPARN, trabalhados e consistidos em planilhas eletrônicas e transferidos para o SIG QGIS Essen 2.14. Os resultados mostraram que a maior precipitação anual, no alto curso da bacia, foi de $1.387,7$ milímetros (mm) (2009) e a menor de $328,5 \mathrm{~mm}$ (2010). No médio curso, a maior precipitação foi de $1.772,4 \mathrm{~mm}$ (2004) e a menor de 609,1 mm (2010). Já no baixo curso, a maior precipitação foi de $2.221,5 \mathrm{~mm}$ (2004) e a menor de $753 \mathrm{~mm}$ (2016). A média pluviométrica dos últimos 20 anos foi de $1036,10 \mathrm{~mm}$, considerada uma precipitação acumulada de seco a normal, com tendência a mais seco. A média do número de dias com chuvas no ano foi de 81 , em torno de 7 dias por mês. O período menos chuvoso está entre os meses de setembro e dezembro e mais chuvoso entre abril e julho. A pequena quantidade de pluviômetros na BHRD-RN, aliado ao curto período de tempo considerado na análise (1997-2016), geraram distorções em relação aos valores totais e médios, mas não influíram na espacialização das chuvas no período estudado, em comparação com os resultados obtidos por Castro (2000).
\end{abstract}

PALAVRAS-CHAVE: clima, bacia hidrográfica, SIG, precipitação

RAINFALL CHARACTERIZATION OF RIO DOCE WATERSHED, NORTHEASTERN REGION OF BRAZIL

ABSTRACT: The Rio Doce watershed (BHRD-RN) in the northeastern region of Brazilis characterized as an area of agricultural activities, mining and urban expansion. The objective of this work was to investigate and spatialize the characteristics of rainfall on the BHRD-RN, between the years of 1997 and 2016, and a comparative analysis of the data used by Castro (2000). The data were obtained in Empresa de Pesquisa Agropecuária do Rio Grande do Norte - EMPARN, worked in spreadsheets and transferred to QGIS Essen 2.14. The results showed that the highest annual rainfall in the upper course of the basin was 1,387.7 millimeters $(\mathrm{mm})(2009)$ and the smallest of $328.5 \mathrm{~mm}$ (2010). In the middle course, the largest precipitation was $1,772.4 \mathrm{~mm}$ (2004) and the lowest of $609.1 \mathrm{~mm}(2010)$. In the lower course, the largest precipitation was 2,221.5 $\mathrm{mm}$ (2004) and the lowest of $753 \mathrm{~mm}$ (2016). The average rainfall of the last 20 years was $1,036.10 \mathrm{~mm}$, considered a dry to normal rainfall, with a tendency to dry. The average number of days with rainfall in the year was 81 , around 7 days per month. The less rainy period is between September and December and wettest between April and July. The small amount of rain gauges on BHRD-RN, coupled with the short period of data obtained (1997-2016), have created distortions in relation to the total and average values, but did not affect the spatialization of rainfall in the studied period, compared to the results obtained by Castro (2000).

KEYWORDS: climate, watershed, GIS, Precipitation. 


\section{CARACTERIZACIÓN LLUVIA DE RIO DOCE CUENCA-RN/BRASIL}

RESUMEN: La cuenca de lo Río Doce-RN/Brasil (BHRD-RN) se caracteriza por ser un área de actividades agrícolas, minería y expansión urbana. El objetivo de este trabajo fue analizar y espacializar las características de las precipitaciones en la BHRD-RN, entre los años de 1997 y 2016, y un análisis comparativo de los datos de Castro (2000). Los datos fueron obtenidos en Empresa de Pesquisa Agropecuária do Rio Grande do Norte EMPARN, trabajados en hojas de cálculo y transferidos a Essen de QGIS SIG 2.14. Los resultados mostraron que la precipitación anual más alta en el curso superior de la cuenca era $1.387,7$ milímetros $(\mathrm{mm})$ (2009) y el más pequeño de 328,5 milímetros (2010). En el curso medio, la mayor precipitación fue $1.772,4 \mathrm{~mm},(2004)$ y la más baja de $609,1 \mathrm{~mm}$ (2010). En el curso inferior, la mayor precipitación fue 2.221,5 mm (2004) y la más baja de $753 \mathrm{~mm}$ (2016). El promedio de precipitaciones de los últimos 20 años fue de 1036,10 mm, considerado un seco para lluvias normales, con tendencia a seco. El número promedio de días con precipitaciones en el año fue de 81 , alrededor de 7 días al mes. El período menos Iluvioso es entre los meses de septiembre y diciembre y lluvioso entre abril y julio. La pequeña cantidad de pluviómetros en BHRD-RN, junto con el corto período de datos obtenidos (1997-2016), ha creado distorsiones en relación con los valores totales y promedio, pero no trabajó en la visualización espacial de la distribución de precipitaciones en el periodo estudiado, en comparación con los resultados obtenidos por Castro (2000).

PALABRAS CLAVE: clima, cuenca, SIG, Precipitación.

\section{INTRODUÇÃO}

Embora esteja localizado próximo à linha do Equador, o Nordeste Brasileiro (NEB) não apresenta uma distribuição de chuvas típicas dessas áreas (KAYANO e ANDREOLI, 2009). Segundo Kayano e Andreoli (2009), o NEB apresenta 03 (três) tipos de climas, com precipitação variando entre 300 e 2000 milímetros $(\mathrm{mm})$ por ano. Esses climas são: o litorâneo úmido, que se estende do litoral da Bahia ao Rio Grande do Norte; o tropical, englobando porções dos Estados da Bahia, Ceará, Maranhão e Piauí; e o tropical semiárido, compreendendo todo o sertão nordestino.

O NEB apresenta acentuada variabilidade interanual, particularmente na precipitação, com alguns anos extremamente secos e outros excessivamente chuvosos. Rao et al (1993) afirmam que no norte do NEB, a principal estação chuvosa ocorre nos meses de março a maio; no sul, de dezembro a fevereiro; e no leste de maio a julho. Para a região do NEB como um todo, a principal estação chuvosa se dá nos meses de abril a julho, período que explica a concentração de $60 \%$ das chuvas anuais. Contrariamente, a estação seca, na maior parte da região do NEB, ocorre entre os meses de setembro e dezembro (RAO et al., 1993).

Segundo Pereira (2014), ao analisarmos no espaço e no tempo as precipitações na região, o semiárido do NEB se apresenta mais susceptível ao surgimento de núcleos de desertificação do que a parte litorânea e o norte da região. Afirma, também, que os períodos secos no semiárido nordestino serão mais extensos ao longo dos anos, e os totais de chuvas diminuirão acentuadamente, principalmente no período seco. Por fim, indica que os Estados do Pernambuco e da Bahia apresentam os veranicos mais longos do NEB; e os Estados do Maranhão e do Piauí apresentam o menor número de dias consecutivos sem chuvas no NEB.

Lucas et al (2009) afirmam que entender a distribuição espacial da pluviosidade é importante para o planejamento e a gestão dos recursos hídricos, 
pois permite analisar a oferta hídrica em uma bacia, bem como avaliar as formas de uso da água, prevenindo possíveis problemas, tais como a contaminação e/ou escassez quali/quantitativa da água.

A importância da caracterização pluviométrica em bacias hidrográficas pode ser observada por trabalhos já publicados acerca dessa temática. Llasat e Rodriguez (1997) elaboraram a sua caracterização pluviométrica, focando, principalmente, nos eventos de grandes chuvas na Europa Mediterrânea. Em um primeiro momento, foi analisada uma série de dados pluviométricos mensais de 16 estações, compreendendo o período de 1940 a 1990. O trabalhou visou comparar as diferentes tendências e anomalias das chuvas. Os mesmos autores também realizaram uma análise da distribuição de eventos pluviais com mais de 200 milímetros, ocorridas em 24 horas, a partir de informações obtidas em 410 estações, no mesmo período, para posterior comparação dos resultados obtidos em cada área estudada.

Bazaraa e Ahmed (1991) caracterizaram a precipitação na cidade de Doha (Catar). Os dados pluviométricos incluíram informações diárias a partir de 1962, bem como temporais, a partir de 1976. Os resultados mostraram que as precipitações, na área em estudo, possuem alta variabilidade e tempestades severas.

Kisaka et al. (2014) examinaram a extensão do período de pluviosidade, ocorrência de secas e a eficácia do uso de técnicas de interpolação na porção oriental do Quênia. Para tanto, foram realizadas análises da variabilidade pluviométrica, utilizando um indexador para anomalias em precipitações, coeficientes de variância e probabilidade de análises. Segundo o autor, o método de interpolação Krigagem se apresentou como a técnica de interpolação geoestatística mais adequada para geração de mapas de precipitação espacial.

Simioni et al. (2014) realizaram a caracterização da precipitação pluviométrica na Bacia Hidrográfica do Rio Ibicuí/RS. Para isso, utilizaram dados pluviométricos de um período temporal de 30 anos, com os quais foi possível gerar isoietas para observar o ano-padrão de chuvas, a precipitação total anual, os anos mais e menos chuvosos e a média anual.

Santos et al. (2014) realizaram o zoneamento da precipitação pluviométrica na Bacia Hidrográfica do Rio Tapajós/PA, com o objetivo de avaliar a distribuição espacial da precipitação ao longo da bacia, definindo as áreas com maiores e menores potenciais de oferta hídrica. Na sua elaboração, foram empregadas análises de séries históricas, definição de acumulados e médias, modelagem por meio de interpoladores e zoneamento das áreas de maior e menor oferta hídrica.

Martins e Rosa (2012) utilizaram as geotecnologias para sistematizar e espacializar os dados climatológicos gerados pelas estações automáticas do Instituto Nacional de Meteorologia (INMET), na Bacia do Rio Paranaíba em Minas Gerais. Os dados foram sistematizados em planilhas eletrônicas e espacializados pelo Método "Inverse Distance Weighted" (IDW), sendo posteriormente convertidos para o formato raster, para recorte e atribuição de uma paleta de cores a fim de demonstrar a variação dos mesmos. Como resultado, observouse que não existe um padrão definido de distribuição espacial dos elementos, devido, em parte, à quantidade insuficiente de informações e à má distribuição espacial das estações pluviométricas. 
Wanderley et al. (2014) utilizaram Redes Neurais Artificiais (RNA's) para propor diferentes procedimentos na interpolação espacial de dados pluviométricos no Estado de Alagoas. Para a realização do estudo, foram utilizadas 245 estações pluviométricas, localizadas nos Estados de Alagoas e Pernambuco, com informações de latitude, longitude, altitude.

As pesquisas supracitadas utilizaram como ferramenta os Sistemas de Informação Geográfica - SIG. Segundo Kisaka et al. (2014), a utilização de técnicas como a IDW, Spline e a interpolação por Krigagem, é importante para estudos ligados ao clima, particularmente aos estudos pluviométricos. Cabe salientar que a área em estudo possui poucas estações pluviométricas, sendo necessária a realização da interpolação dos dados visando reavaliar dados considerados inconsistentes, bem como contornar o problema de dados ausentes.

A técnica de interpolação permite elaborar um novo conjunto de dados, a partir de um conjunto discreto de dados pontuais já conhecidos, "permitindo a análise para regiões que não dispõem de registros, em decorrência da ausência de estação de medição, ou que apresentem falhas em seu banco de dados" (WANDERLEY et al., 2014).

Diante do exposto, o presente trabalho realizou uma caracterização pluviométrica da Bacia Hidrográfica do Rio Doce - RN, com o objetivo de investigar, espacializar e divulgar as principais características da distribuição das precipitações na bacia, tais como média anual, meses e anos chuvosos e total de dias e meses com chuvas. A pesquisa teve como base os dados pluviométricos registrados entre os anos de 1997 e 2016. Para ratificar os resultados, fez-se uma análise comparativa dos dados pluviométricos trabalhados por Castro (2000) para a bacia, no período de 1910 a 1979. Os resultados obtidos poderão servir de base para um melhor planejamento na ocupação e uso do solo da bacia visando, principalmente, as sustentabilidades econômica e ambiental.

\section{MATERIAIS E MÉTODOS}

\subsection{CARACTERIZAÇÃO DA ÁREA DE ESTUDO}

A Bacia Hidrográfica do Rio Doce está localizada na porção leste do Estado do Rio Grande do Norte, sendo limitada pelos paralelos $05^{\circ} 48^{\prime} 00^{\prime \prime}$ e $05^{\circ}$ $36^{\prime}$ 00" S e pelos meridianos $035^{\circ} 42^{\prime}$ 00" e $035^{\circ}$ 36' 00" W Gr., DATUM SIRGAS 2000, compreendendo uma área de $396,7 \mathrm{~km}^{2}$ (COSTA et al., 2016) (FIGURA 1).

Localizada na porção leste do NEB e do Estado do Rio Grande do Norte, a Bacia Hidrográfica do Rio Doce (BHRD-RN) constitui uma unidade geográfica com diversas formas de ocupação, desde a agricultura familiar aos parques fabris e industriais. As ocupações urbanas também ocorrem em Zonas de Proteção Ambiental. A BHRD-RN é formada pelos rios Guajirú e do Mudo, sendo esses seus principais afluentes, que desembocam na Lagoa de Extremoz, transformando-se, à jusante desta, no rio que dá nome à bacia. 


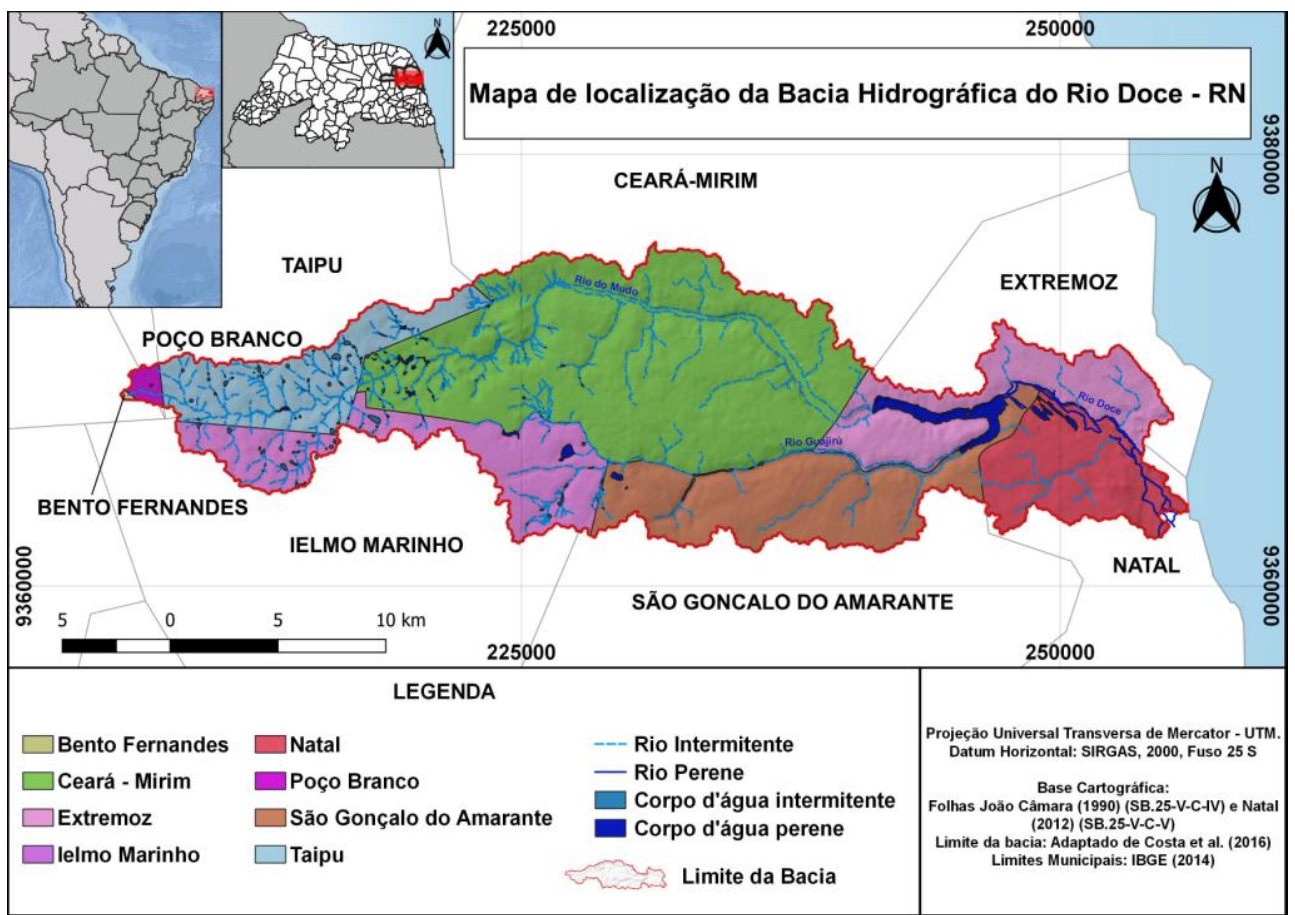

Figura 1 - Localização da área em estudo. Fonte: Adaptado de Costa et al. (2016).

Essa bacia é uma das mais importantes da Região Metropolitana de Natal (RMN), especialmente para a Zona Norte do Município de Natal, onde se encontra a Lagoa de Extremoz que é a maior fonte de abastecimento d'água da região. A bacia recobre partes de 8 (oito) municípios, quais sejam, Ceará-Mirim, Extremoz, Natal, Ielmo Marinho, São Gonçalo do Amarante, Taipu, Poço Branco e Bento Fernandes, onde atuam diversos atores sociais, a saber: produtores rurais, empresários e a sociedade civil como um todo.

Segundo Castro (2000), o rio Doce tem origem na Lagoa de Extremoz, que é alimentada pelos rios intermitentes Guajirú e do Mudo, principais tributários da bacia, localizados a montante dessa lagoa. A geologia da bacia compreende sedimentos tércio-quaternários e quaternários, que repousam sobre rochas pré-cambrianas do embasamento cristalino.

Cunha (2004) afirma que esse rio corre sobre sedimentos quaternários de dunas e aluviões até a sua desembocadura, sendo alimentado por vários olheiros em aproximadamente $14 \mathrm{~km}$ de percurso, já que seu leito está localizado em um nível mais baixo que o nível estático das águas.

A evolução paleogeográfica nas cercanias da foz da bacia foi complexa, por estar ligada ao desenvolvimento do campo de dunas que contorna e desvia sua desembocadura e a rede de drenagem natural, formando lagoas alinhadas que, em determinadas ocasiões, comunicam-se entre si. Cunha (2004) afirma que houve uma migração de alguns quilômetros da sua desembocadura, como resposta à ação eólica existente.

No ano de 1965, para evitar o total soterramento do curso do rio pelo avanço das dunas, o Departamento Nacional de Obras e Saneamento - DNOS canalizou o rio através de dragagens e outras obras superficiais, levando seu 
curso para o estuário do rio Potengi, através do Canal de Manimbu (CUNHA, 2004). O autor relata, ainda, que estudos batimétricos de detalhe, realizados em setembro de 2001, permitiram observar um paleocanal do rio Doce, comprovado a partir de levantamentos geofísicos com registros na área de póspraia da Redinha Nova.

A geomorfologia na BHRD-RN está representada por unidades da Depressão Sertaneja, Tabuleiros, Dunas fixas e móveis, Planície Flúvio-Marinha e Planície de Inundação Fluvial (IDEMA, 2012). Os solos são classificados, de acordo com EMBRAPA (2006), em Neossolo Quartzarênico, Latossolo Amarelo Distrófico, Planossolo solódico, Solos Indiscriminados de Mangue e o Argissolo Vermelho-Amarelo Eutrófico (IGARN, 2009).

Em relação ao clima, Felipe et al. (2006) elaboraram o mapa das unidades climáticas do Estado, a partir de dados obtidos no Instituto de Desenvolvimento do Rio Grande do Norte, subdividindo-as em 5 (cinco) tipos de clima: Úmido, Sub-úmido, Sub-úmido seco, Semiárido e Semiárido Rigoroso (FIGURA 2A).

A BHRD-RN está localizada nas unidades climáticas Sub-úmido e Subúmido Seco. Segundo os mesmos autores, o clima Sub-úmido é caracterizado por médias pluviométricas anuais que variam entre 800 e 1200 milímetros. Equivale, na classificação de Köppen, ao clima tropical chuvoso, com estação chuvosa começando entre fevereiro e março, prolongando-se até os meses de agosto e setembro. Ainda segundo estes autores, o clima Sub-úmido seco possui média de precipitação entre 600 e 800 milímetros. Equivale na classificação de Köppen à transição entre o Tropical Típico (Aw) e o Semiárido (Bs).

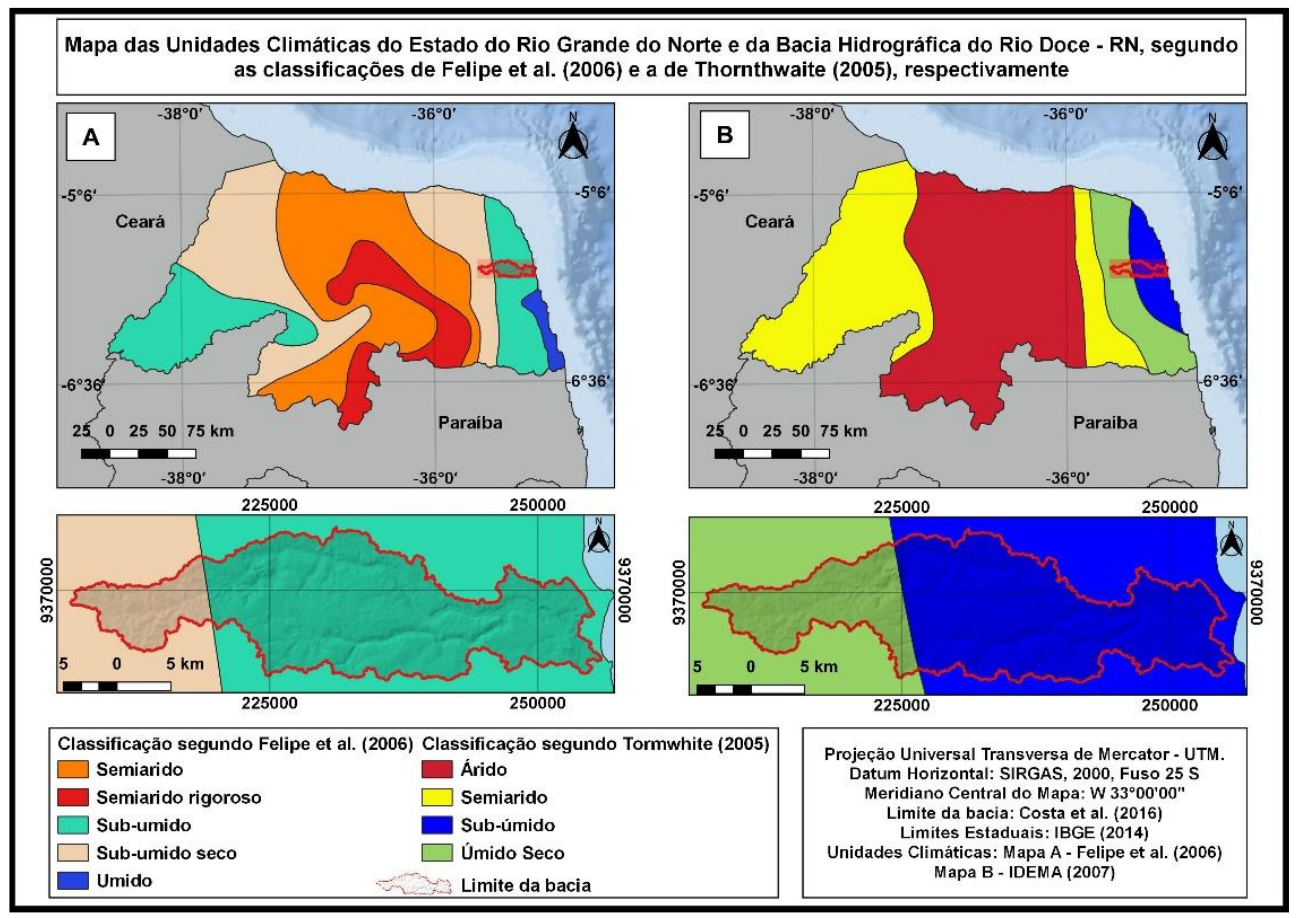

Figura 2 - Mapa das unidades climáticas da BHRD-RN, a partir de Felipe et al. (2006) (A) e SEMARH (2005) (B). 
Já na classificação da SEMARH (2005) (FIGURA 2B), que teve como referência a classificação de Thornthwaite (1948), a bacia está inserida nas unidades Sub-úmido (C1DA'a') e Úmido seco (C1WA'a'). A primeira unidade tem como característica um clima seco e sub-úmido, com pequeno ou nenhum excesso de água, megatérmico e com baixa variação estacional. Já o úmido seco tem como característica um clima seco e sub-úmido, moderado excesso de água, megatérmico e baixa variação estacional. Percebeu-se que ambas as classificações mostram uma área de transição das unidades climáticas existentes na bacia, partindo de leste para oeste, com menores precipitações.

A classificação mais aceita e adequada para a bacia é a da SEMARH (2000), que, a partir da classificação de Köppen, caracteriza o clima como predominantemente do tipo $\mathrm{As}^{\prime}$ - clima tropical chuvoso com verão seco (SEMARH, 2000). A estação chuvosa se aproxima no período do outono (entre março e junho); as chuvas anuais médias crescem do interior para o litoral, passando de 700 milímetros nas cabeceiras para 1.400 milímetros na foz.

Em relação à precipitação, Castro (2000) realizou uma caracterização na BHRD-RN, tendo como referência os dados dos Postos Pluviométricos dos municípios de Taipu (alto curso do rio), Ceará-Mirim (médio curso), do período de 1912 e 1976, e Natal (baixo curso), com dados dos anos de 1910 a 1979. Segundo a autora, a maior precipitação pluviométrica no alto curso da bacia foi de $2432 \mathrm{~mm}$ e a menor de $306 \mathrm{~mm}$. A média obtida no mesmo período foi de 733,29 mm. No médio curso, a maior precipitação foi de $2098 \mathrm{~mm}$ e a menor de $382 \mathrm{~mm}$, com média anual de $1032,65 \mathrm{~mm}$. Já no baixo curso, a maior precipitação foi de $3511 \mathrm{~mm}$ e a menor de $530 \mathrm{~mm}$, com média anual de 1563 $\mathrm{mm}$.

A temperatura média, no médio curso da bacia, foi de $25,4^{\circ} \mathrm{C}$, com variações de $24^{\circ} \mathrm{C}$ a $26,5^{\circ} \mathrm{C}$ e amplitude térmica de $2,5^{\circ} \mathrm{C}$. Já no baixo curso, as temperaturas variaram entre $24,4^{\circ} \mathrm{C}$ e $27,3^{\circ} \mathrm{C}$, com média anual de $26,2^{\circ} \mathrm{C}$ e amplitude térmica de $2,9^{\circ} \mathrm{C}$. Em toda a bacia, os meses mais quentes são dezembro, janeiro e fevereiro e os mais frios são julho, agosto e setembro (CASTRO, 2000).

Somando-se as médias obtidas por Castro (2000), a média pluviométrica da bacia para o período analisado foi de $1109,65 \mathrm{~mm}$. Já a temperatura média da bacia variou entre $24^{\circ} \mathrm{C}$ e $27,3^{\circ} \mathrm{C}$ com uma amplitude térmica de $3,3^{\circ} \mathrm{C}$.

\subsection{OBTENÇÃO E ORGANIZAÇÃO DOS DADOS}

A obtenção dos dados pluviométricos foi realizada no site da Empresa de Pesquisa Agropecuária do Estado do Rio Grande do Norte - EMPARN, que fornece os dados diários das chuvas por município desde o ano de 1992 até os dias atuais.

Além das chuvas diárias, a empresa fornece também dados relativos às médias mensais e anuais, bem como gráficos e mapas que demonstram a distribuição das chuvas por todo o Estado. Os dados precisam ser transferidos para planilhas eletrônicas para posterior análise. Para o presente trabalho, foram analisados os dados dos últimos 20 anos (1997 - 2016) de 08 pontos pluviométricos, tendo como referência os municípios pertencentes à bacia. 
Algumas observações pluviométricas apresentaram falhas (ausências) em seus registros. Entretanto, como é necessário trabalhar com dados contínuos, daí, então, para realizar o preenchimento dessas lacunas, calculou-se a média aritmética dos postos vizinhos. Este método consiste em calcular a média aritmética de pelo menos 03 (três) estações pluviométricas vizinhas à estação com a lacuna de dados (PAULHUS; KOHLER, 1952). Segundo os autores, esse procedimento é usado se a precipitação normal anual em cada uma das 03 (três) estações vizinhas for diferente, no máximo, até $10 \%$ da estação com falha.

Os dados foram inseridos em planilhas eletrônicas e as lacunas foram preenchidas para que se pudesse então obter-se a média anual dos municípios e da bacia no período de 20 anos (TABELA 1).

Tabela 1 - Média, por município, das precipitações entre os anos de 1997 e 2016. Fonte: EMPARN, 2017.

\begin{tabular}{cccc}
\hline $\mathbf{X}$ & $\mathbf{Y}$ & Municípios & $\begin{array}{c}\text { Média por } \\
\text { município }\end{array}$ \\
\hline 188492 & 9371869 & Bento Fernandes & 624,82 \\
\hline 234606 & 9380968 & Ceará - Mirim & 1164,04 \\
\hline 248651 & 9371567 & Extremoz & 1227,20 \\
\hline 217556 & 9360030 & Ielmo Marinho & 961,21 \\
\hline 253169 & 9358042 & Natal & 1720,31 \\
\hline 201481 & 9383475 & Poço Branco & 664,03 \\
\hline 238148 & 9359730 & $\begin{array}{c}\text { São Gonçalo do } \\
\text { Amarante }\end{array}$ & 1243,36 \\
\hline 213594 & 9380735 & Taipu & 692,86 \\
\hline \multicolumn{5}{c}{ Média total } & & 1036,10 \\
\hline
\end{tabular}

A planilha eletrônica finalizada foi salva no formato separado por vírgulas (*.csv), para ser inserida no Banco de Dados Geográficos - BDG do Sistema de Informação Geográfica - SIG QGIS Essen 2.14. Além dos dados pluviométricos foram utilizadas as coordenadas planas (UTM) das estações meteorológicas que forneceram os dados pluviométricos para a espacialização dos dados.

Esses dados serviram de base para a elaboração do mapa da distribuição pluviométrica na BHRD-RN, apresentado em tonalidades que variaram do azul mais escuro (maiores pluviometrias) ao vermelho (menores pluviometrias).

\subsection{PREPARAÇÃO DO PROJETO E DO BANCO DE DADOS GEOGRÁFICOS NO AMBIENTE SIG}

O Banco de Dados Geográficos - BDG foi construído no ambiente do Sistema de Informações Geográficas - SIG QGIS Essen 2.14, com dados vetoriais pontuais e poligonais, em formato shapefile (*.shp). Além das informações pontuais dos pluviômetros, foram inseridos o polígono representando o limite da bacia (COSTA et al., 2016) e os limites municipais (IBGE, 2014). 
O projeto e os dados vetoriais foram gerados com o sistema de coordenadas UTM, Datum SIRGAS 2000, Fuso 25, Hemisfério Sul, cuja. EPSG escolhida foi a 31985.

\subsection{MÉTODOS APLICADOS PARA ELABORAÇÃO DOS RESULTADOS (MAPAS E GRÁFICOS)}

Os dados secundários obtidos na EMPARN foram inseridos na planilha eletrônica para a elaboração dos mapas referentes às características pluviométricas da BHRD-RN. Os dados são referentes às chuvas diárias, mensais e anuais, dos anos de 1997 a 2016.

Para a identificação dos anos mais e menos chuvosos na bacia, Castro (2000) teve como referência 01 (uma) estação pluviométrica para os trechos do alto, médio e baixo curso da BHRD-RN. Para o presente trabalho, uniram-se os dados dos pluviômetros instalados nos municípios pertencentes a bacia e realizou-se a média aritmética simples. O objetivo foi aproximar-se da média das precipitações por trecho com mais dados espaciais, em relação a trabalhos anteriores, como o de Castro (2000).

Os procedimentos para a organização dos dados pluviométricos da BHRD-RN foram os seguintes:

- Para as estações pluviométricas que apresentaram "anos" sem coleta, calculou-se a média aritmética das 03 estações mais próximas, denominada Método da Média Aritmética dos postos vizinhos (Garcez; Alvarez, 1988);

- Para os dias de chuva sem coleta, calculou-se uma média aritmética das mesmas datas, durante os 20 anos (1997 - 2016), a partir de uma planilha eletrônica;

- $\quad$ Com a planilha definida, foram calculados os valores médios da precipitação diária, mensal e, por fim, os da precipitação anual.

Para isto, foi elaborada uma tabela em formato separado por vírgulas (*.csv), depois inseridos no SIG QGIS. Com a janela aberta, o passo seguinte foi a busca do arquivo dos dados, a inserção do nome da camada, a escolha do formato do arquivo (utilizando o ícone "delimitadores personalizados") e, posteriormente, escolheu-se os itens "ponto e vírgula" e "tabulação". Na opção "definição de geometria", com as coordenadas inseridas na tabela, optou-se pelo ícone "coordenadas de ponto", definindo os campos X e Y para importação dos dados (FIGURA 3).

A distribuição dos 08 (oito) pontos com informações das precipitações, se deu a partir da localização dos pontos pluviométricos existentes em cada município da bacia. 


\begin{tabular}{|c|c|c|c|c|c|c|c|c|c|c|c|c|c|}
\hline \multicolumn{12}{|c|}{ Criar uma camada a partir de arquivo de texto delimitado } & \multicolumn{2}{|r|}{$\times$} \\
\hline \multicolumn{12}{|c|}{ Nome do Arquivo C:/Users/Franklin/Media_anual_EMPARN.csv } & \multicolumn{2}{|c|}{ Procurar... } \\
\hline \multicolumn{10}{|c|}{ Nome da camada Media_anual_EMPARN } & \multicolumn{4}{|c|}{ Codificação System } \\
\hline \multirow{3}{*}{\multicolumn{3}{|c|}{ Formato do arquivo }} & \multicolumn{4}{|c|}{ csv (texto separado por delimitador) } & Delimitad & dores perso & onalizados & \multicolumn{4}{|c|}{ Delimitador de expressão regular } \\
\hline & & & \multirow{2}{*}{\multicolumn{2}{|c|}{\begin{tabular}{|l}
$\square$ Virgula \\
Outros delimitadores \\
\end{tabular}}} & \multicolumn{2}{|c|}{ ఐ Tabulação } & \multicolumn{2}{|c|}{$\square$ Espaço } & \multicolumn{2}{|c|}{$\square$ Dois pontos } & \multicolumn{3}{|c|}{$\square$ Ponto e vírgula } \\
\hline & & & & & & & Citação & 0 & & \multicolumn{2}{|c|}{ Escape -} & & \\
\hline \multicolumn{3}{|c|}{ Op̧̧ões de registro } & \multicolumn{11}{|c|}{ Número de linhas de cabeçalho a descartar $0 \quad \square \square$ Primeiro registro tem nomes de campos } \\
\hline \multicolumn{3}{|c|}{ Opş̃es do campo } & \multicolumn{11}{|c|}{$\square$ Aparar campos $\square$ Descartar campos vazios $\square$ Separador decimal é a vírgula } \\
\hline \multirow{2}{*}{\multicolumn{3}{|c|}{ Definição de geometria }} & (C) Coordena & das de pon & & \multicolumn{3}{|c|}{ Texto bem conhecido (WKT) } & \multirow{2}{*}{\multicolumn{3}{|c|}{$\begin{array}{l}\text { Sem geometria (atributo a } \\
-\square \text { coordenadas GMS }\end{array}$}} & apenas de & tabela) \\
\hline & & & Campo X $\mathrm{X}$ & & $\checkmark$ & Campo $Y$ & Y & & & & & & \\
\hline \multicolumn{6}{|c|}{ Configurações da camada $\square$ Usar indice espacial } & \multicolumn{4}{|c|}{$\square$ Usar indice de subgrupos } & \multicolumn{2}{|c|}{$\square$ Olhar arquivo } & & \\
\hline & $\mathrm{x}$ & $\mathrm{Y}$ & Municipios & 1997_1 & $1998 \_1$ & 1999_1 & $2000 \_1$ & 2001 & $2002 \_1$ & 2003_1 & 2004 & $2005 \_1$ & $200 \wedge$ \\
\hline 1 & 188492 & 9371869 & Bento Fernandes & 596,00 & 555,10 & 380,50 & 1085,90 & 476,90 & 749,60 & 576,20 & 1248,00 & 567,40 & 455, \\
\hline 2 & 234606 & 9380968 & Ceará - Mirim & 1068,40 & 1608,70 & 1285,60 & 1491,80 & 921,60 & 1729,80 & 1638,00 & 1853,40 & 1226,50 & 937, \\
\hline $3:$ & 248651 & 9371567 & Extremoz & 1106,30 & 1514,87 & 1043,17 & 1912,40 & 977,63 & 1678,80 & 1425,17 & 1996,93 & 1537,40 & 925 , \\
\hline $4:$ & 217556 & 9360030 & Ielmo Marinho & 897,10 & 1271,97 & 829,07 & 1571,83 & 704,30 & 1295,50 & 1111,53 & 1514,77 & 744,60 & 688 \\
\hline 5 & 253169 & 9358042 & Natal & 1187,30 & 1641,20 & 1111,20 & 2239,40 & 1276,50 & 2026,70 & 1523,60 & 2446,10 & 2026,70 & 158: \\
\hline \multirow[t]{2}{*}{$\begin{array}{l}6 \\
<\end{array}$} & 201481 & १३२83475 & Porn Rranen & $604.0 n$ & 798.80 & $447.6 n$ & 1123.70 & 497.20 & 796.40 & $478.0 n$ & 979.10 & 773.10 & $\begin{array}{c}463 . \\
>\end{array}$ \\
\hline & & & & & & & & & \multicolumn{2}{|l|}{ OK } & Cancelar & \multicolumn{2}{|c|}{ Ajuda } \\
\hline
\end{tabular}

Figura 3 - Janela da criação da camada dos pontos de coleta dos dados de chuvas da BHRD-RN.

Na interpolação dos dados, aplicou-se a técnica do Inverso do Quadrado da Distância - IDW ou IQD, para gerar o arquivo raster no formato*.tiff, apresentando como resultado uma série de mapas representando informações relativas à média diária, mensal e anual das precipitações na bacia.

Segundo Marcuzzo et al. (2011), esse método é utilizado, com frequência, para interpolar e gerar modelos digitais de terreno, bem como para fazer estudos do comportamento espacial e temporal da chuva a partir da espacialização da precipitação nas bacias hidrográficas.

O método de interpolação IDW é uma ferramenta de análise espacial em que cada amostra assume uma influência local, diminuindo a partir da distância. Segundo Amorim et al. (2008), esse método admite que os pontos mais próximos influem mais que os pontos mais afastados. No QGIS, essa ferramenta está localizada no menu da barra de ferramentas denominada "raster", e, posteriormente, no menu "interpolação". Com a janela aberta, na parte da entrada, selecionou-se a camada vetorial com os pontos pluviométricos e, na definição da interpolação, foram escolhidas as variáveis para cada mapa temático (FIGURA 4). 


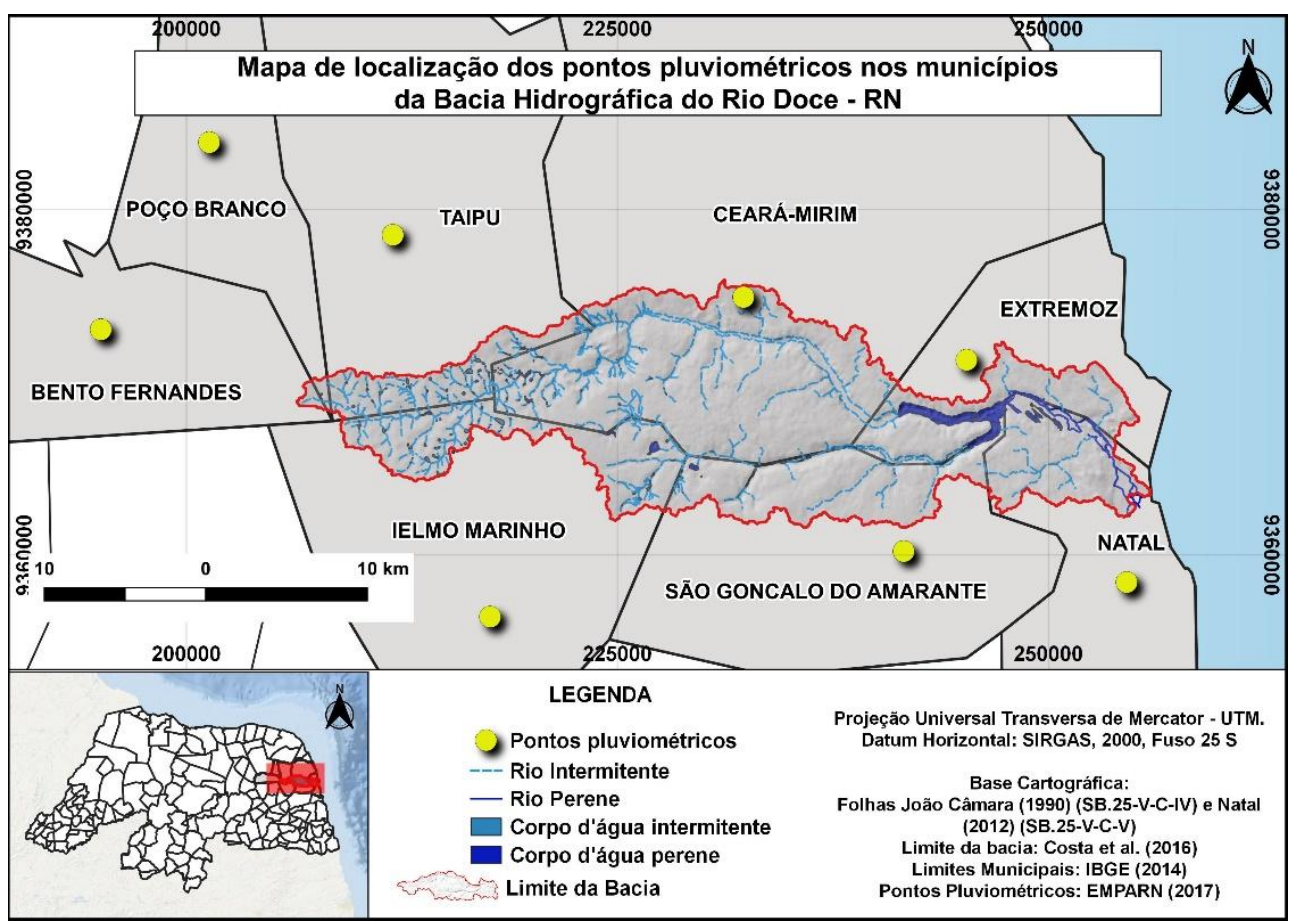

Figura 4 - Localização dos pontos pluviométricos considerados.

Como forma de saída, escolheu-se o método de interpolação (IDW) e o tamanho das células $X$ e $Y$ de 30 x 30 metros. A área de interpolação foi definida como sendo maior que a área da bacia, para que se pudesse fazer o recorte do limite geográfico da BHRD-RN. Para que isso ocorresse, aumentou-se a área de extensão na tela do QGIS, e utilizou-se o ícone "Definir pela extensão atual". O passo seguinte foi inserir o nome do arquivo de saída (FIGURA 5).

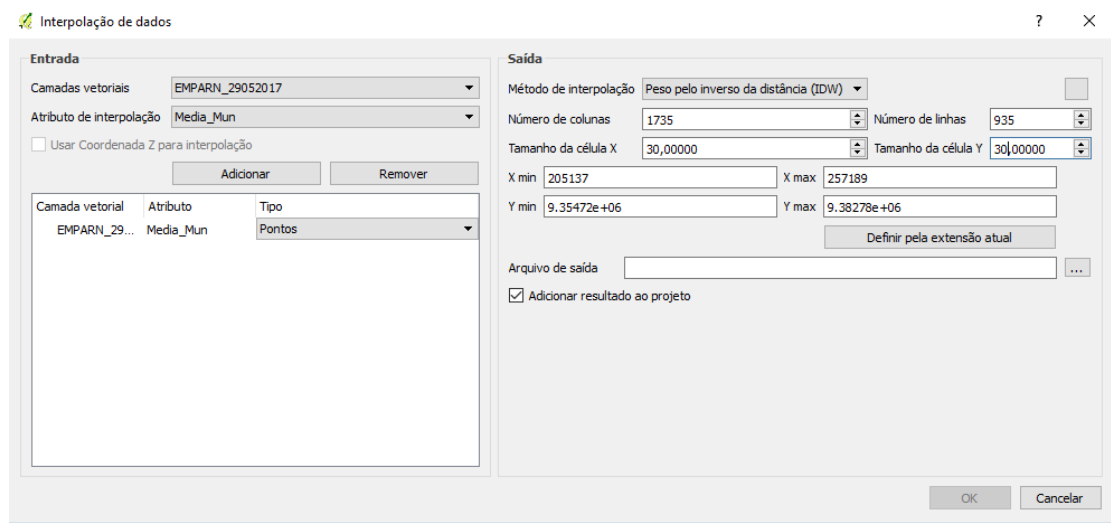

Figura 5 - Janela da criação da camada dos pontos de coleta dos dados de chuvas da BHRD-RN.

O produto gerado foi um arquivo raster, formato Tagged Image File Format (*.tiff), com as manchas relativas à distribuição espacial da precipitação anual da BHRD-RN, em escala de níveis de cinza. Fez-se a coloração dos intervalos com tons degradê que variaram do azul escuro (maiores precipitações) ao azul claro (menores precipitações). 
Após a interpolação, o passo seguinte foi a extração das isoietas, acionando-se no software QGIS, a extração dos contornos.

$\mathrm{Na}$ janela aberta, escolheu-se o arquivo de entrada (Imagem interpolada), o arquivo de saída, o intervalo entre isoietas e o nome do atributo necessário para a construção do BDG da variável analisada.

O intervalo entre as isoietas foi definido como 50, construindo-se, assim, isoietas com intervalos de 50 milímetros de precipitação na bacia.

\section{RESULTADOS E DISCUSSÃO}

\subsection{ANÁLISE DAS PRECIPITAÇÕES ANUAIS NA BHRD-RN} BHRD-RN.

A Figura 6 apresenta o gráfico da média das precipitações anuais na

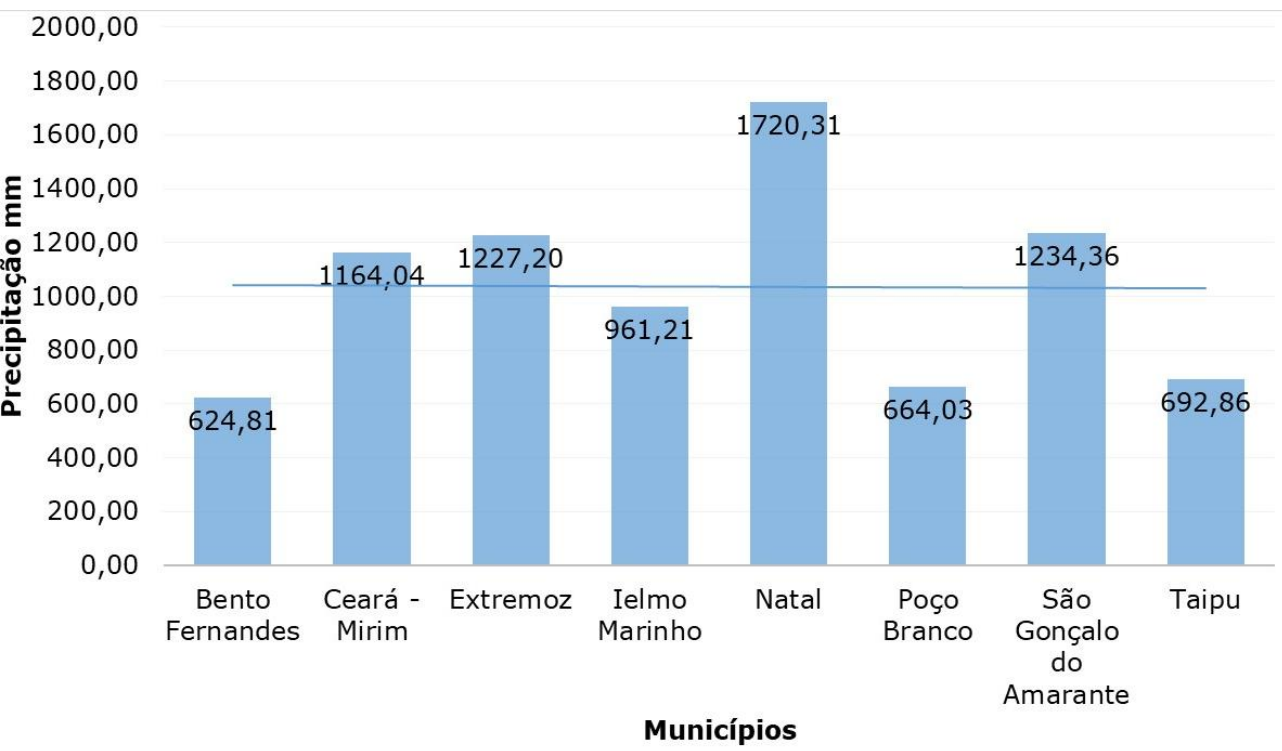

Figura 6 - Gráfico representando a média da precipitação anual, por município, na BHRD-RN (1997 - 2016).

A média pluviométrica anual na bacia, entre os anos de 1997 e 2016, é de 1036,10 milímetros $(\mathrm{mm})$. Desta média, Natal possui a maior delas, com 1720,31 milímetros, seguido pelos municípios de Extremoz, com 1227,20 mm; São Gonçalo do Amarante, com 1234,36 mm e Ceará-Mirim; com 1164,04 mm; estes últimos localizados na porção centro-leste da bacia, mais próximos do litoral, também com valores acima da média anual da bacia. Já Ielmo Marinho, com 961,21 mm; Taipu, com 692,86 mm, Poço Branco, com 664,03 mm e Bento Fernandes, com 624,82 mm, localizados na porção centro-oeste da bacia, e mais afastados do litoral e, portanto, com mais influência do clima semiárido, apresentam as menores médias pluviométricas, abaixo, portanto, da média anual geral da bacia (FIGURA 7).

Na Figura 7 observa-se que, afastando-se do litoral, a precipitação diminui consideravelmente, chegando ao extremo oeste da bacia com uma média anual que é a metade do valor da precipitação média anual do extremo leste. A zona de transição entre as áreas de maior e menor precipitação anual 
está na porção central da bacia, onde se pode perceber, pelas isoietas, que, a partir do município de Ceará-Mirim, na direção oeste, as precipitações estão abaixo da média anual da bacia.

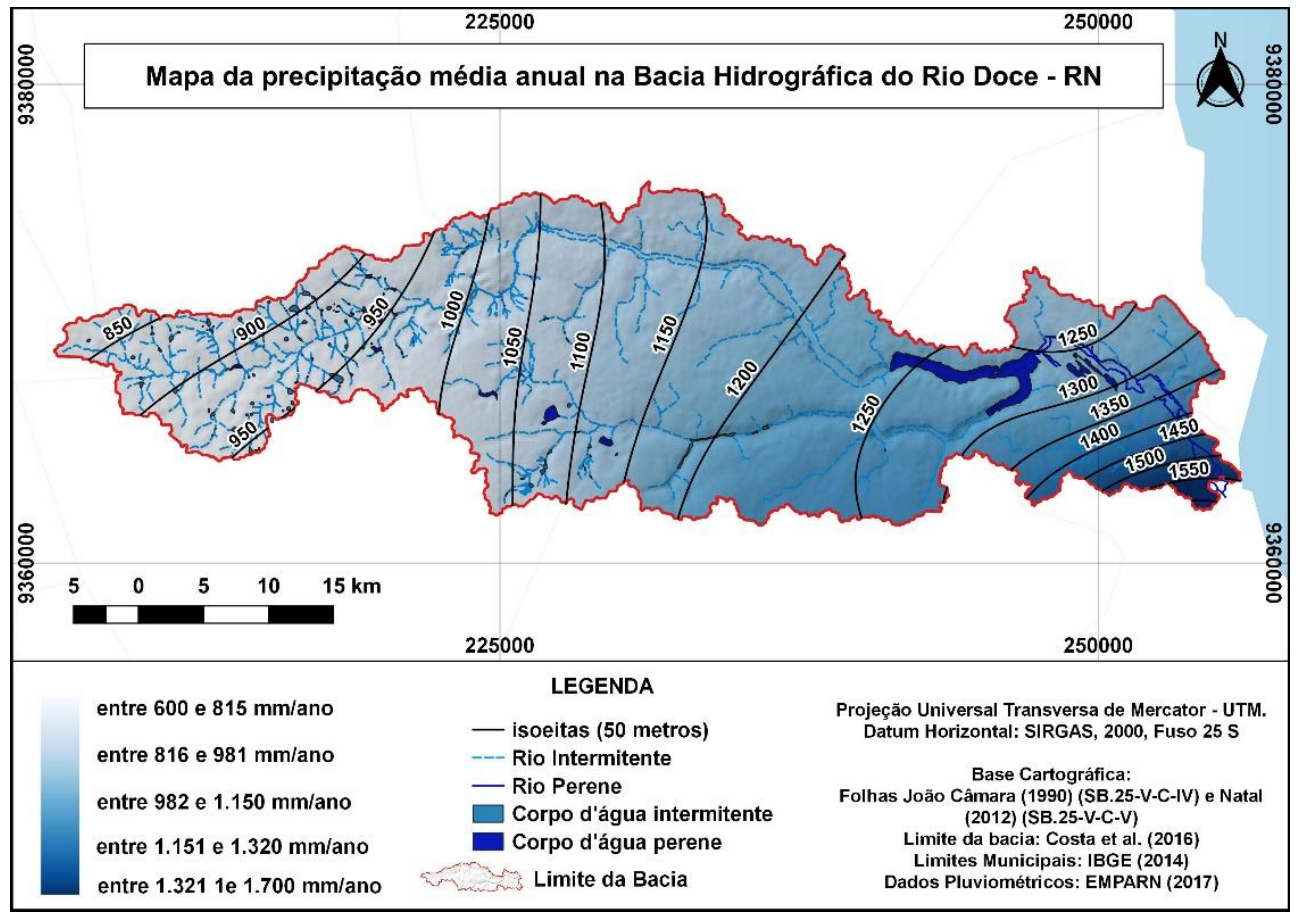

Figura 7 - Mapa da média pluviométrica anual na BHRD-RN (1997 - 2016), a partir dos dados da EMPARN de 2017.

No período analisado, a maior precipitação anual, no alto curso da bacia, foi de $1387,7 \mathrm{~mm}$, no ano de 2009, e a menor, de $328,5 \mathrm{~mm}$, no ano de 2010 . A média obtida, no período, para o alto curso foi de $735,7 \mathrm{~mm}$. No médio curso, a maior precipitação foi de $1772,4 \mathrm{~mm}$, no ano de 2004 , e a menor, de 609,1 $\mathrm{mm}$, no ano de 2010. A média anual, desse trecho da bacia, foi de 1199,2 mm. Já no baixo curso, a maior precipitação foi de $2221,5 \mathrm{~mm}$, no ano de 2004 , e a menor, de $753 \mathrm{~mm}$, no ano de 2016, com média anual de 1473,8 mm para o período analisado.

Na Bacia Hidrográfica do Rio Doce, foram analisados os dados pluviométricos relativos aos 8 municípios pertencentes à bacia, distribuídos em 5 microrregiões: Baixa Verde (Bento Fernandes e Poço Branco), Litoral Nordeste (Taipu), Macaíba (Ceará-Mirim, São Gonçalo do Amarante), Natal (Natal e Extremoz), Agreste Potiguar (Ielmo Marinho). Para cada Microrregião, a EMPARN (2017) adotou intervalos de valores, em quantis, que caracterizam a precipitação anual acumulada como muito seco, seco, normal e muito chuvoso (Tabela 2).

De acordo com a Tabela 2, observa-se que a média da bacia está caracterizada entre o período seco e normal, com predominância do período seco. Analisando isoladamente cada município, Extremoz e Taipu se apresentaram como os mais secos no período, enquanto Ielmo Marinho foi o único a apresentar, como característica, um período normal a chuvoso. Os demais municípios estiveram na média da bacia como um todo, de seco a normal. 
Tabela 2 - Caracterização da precipitação acumulada, por ano, entre 1997 e 2016

\begin{tabular}{ccccccc}
\hline Municípios & $\begin{array}{c}\text { Média da } \\
\text { Pluviosidade } \\
\text { anual }(\mathrm{mm})\end{array}$ & $\begin{array}{c}\text { Muito } \\
\text { Seco }\end{array}$ & Seco & Normal & $\begin{array}{c}\text { Muito } \\
\text { Chuvoso }\end{array}$ & $\begin{array}{c}\text { Característica da } \\
\text { precipitação } \\
\text { acumulada no ano }\end{array}$ \\
\hline Bento Fernandes & $\mathbf{6 2 4 , 8}$ & 389,21 & 528,12 & 740,72 & 1005,71 & Seco a Normal \\
\hline Ceará - Mirim & $\mathbf{1 1 6 4 , 0}$ & 826,66 & 1101,9 & 1478,4 & 1779,23 & Seco a Normal \\
\hline Extremoz & $\mathbf{1 2 2 7 , 2}$ & 1185,77 & 1581,7 & 2015,2 & 2263,51 & Muito seco a seco \\
\hline Ielmo Marinho & $\mathbf{9 6 1 , 2}$ & 448,96 & 572,24 & 781,58 & 1071,51 & Normal a chuvoso \\
\hline Natal & $\mathbf{1 7 2 0 , 3}$ & 1185,77 & 1581,7 & 2015,2 & 2263,51 & Seco a Normal \\
\hline Poço Branco & $\mathbf{6 6 4 , 0}$ & 389,21 & 528,12 & 740,72 & 1005,71 & Seco a Normal \\
\hline $\begin{array}{c}\text { São Gonçalo do } \\
\text { Amarante }\end{array}$ & $\mathbf{1 2 3 4 , 4}$ & 826,66 & 1101,9 & 1478,4 & 1779,23 & Seco a Normal \\
\hline Taipu & $\mathbf{6 9 2 , 9}$ & 713,47 & 889,72 & 1216,17 & 1642,12 & Muito seco \\
\hline Media & $\mathbf{1 0 3 6 , 1 0}$ & $\mathbf{7 4 5 , 7 1}$ & $\mathbf{9 8 5 , 6 8}$ & $\mathbf{1 3 0 8 , 3 0}$ & $\mathbf{1 6 0 1 , 3 2}$ & SECO A NORMAL \\
\hline
\end{tabular}

Fonte: EMPARN, 2017.

\subsection{NÚMERO DE DIAS CHUVOSOS POR MESES NA BHRD-RN}

A média pluviométrica diária da bacia, entre os anos de 1997 e 2016, foi de 07 (sete) dias de chuva por mês, ao longo do ano. Os municípios acima da média foram Natal (14 dias) e Extremoz (08 dias). Os municípios de CearáMirim e São Gonçalo do Amarante estiveram na média da bacia (7 dias). Abaixo da média estão os municípios de Poço Branco ( 6 dias), Ielmo Marinho (5 dias), Bento Fernandes (4 dias) e Taipu (3 dias) (FIGURA 8).



Meses

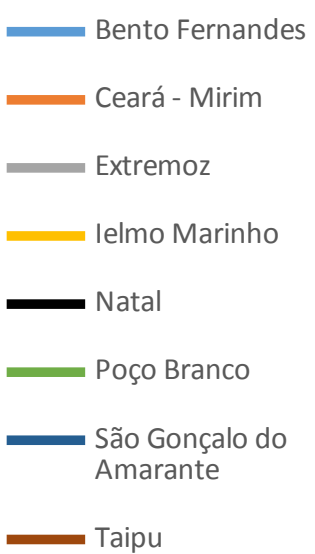

Taipu

Figura 8 - Gráfico representando a média da precipitação diária, por meses e por município, na BHRD-RN, a partir de dados obtidos na EMPARN, em 2017.

De acordo com a Figura 08, observa-se que há uma tendência de aumento dos dias chuvosos entre janeiro e março (6 a 9 dias). A partir do mês 
de abril, até o mês de julho, o número de dias chuvosos aumenta, bem como o volume de água. Considera-se esse período o mais chuvoso na bacia.

A partir de julho, o número de dias com precipitação diminui, bem como o volume d'água. Considera-se o período entre setembro e dezembro como o mais seco na bacia, com a média máxima de 4 dias com chuvas (setembro) e a mínima de 2 dias (outubro e novembro).

No período de um ano, a média de dias chuvosos foi de 81 , equivalentes a aproximadamente 3 meses por ano. Os municípios com mais meses chuvosos, no período de 01 (um) ano, foram Natal (06 meses), seguido de Extremoz, São Gonçalo do Amarante e Ceará-Mirim (3 meses). Os demais municípios apresentaram menos de 3 meses de chuvas por ano (FIGURA 9).

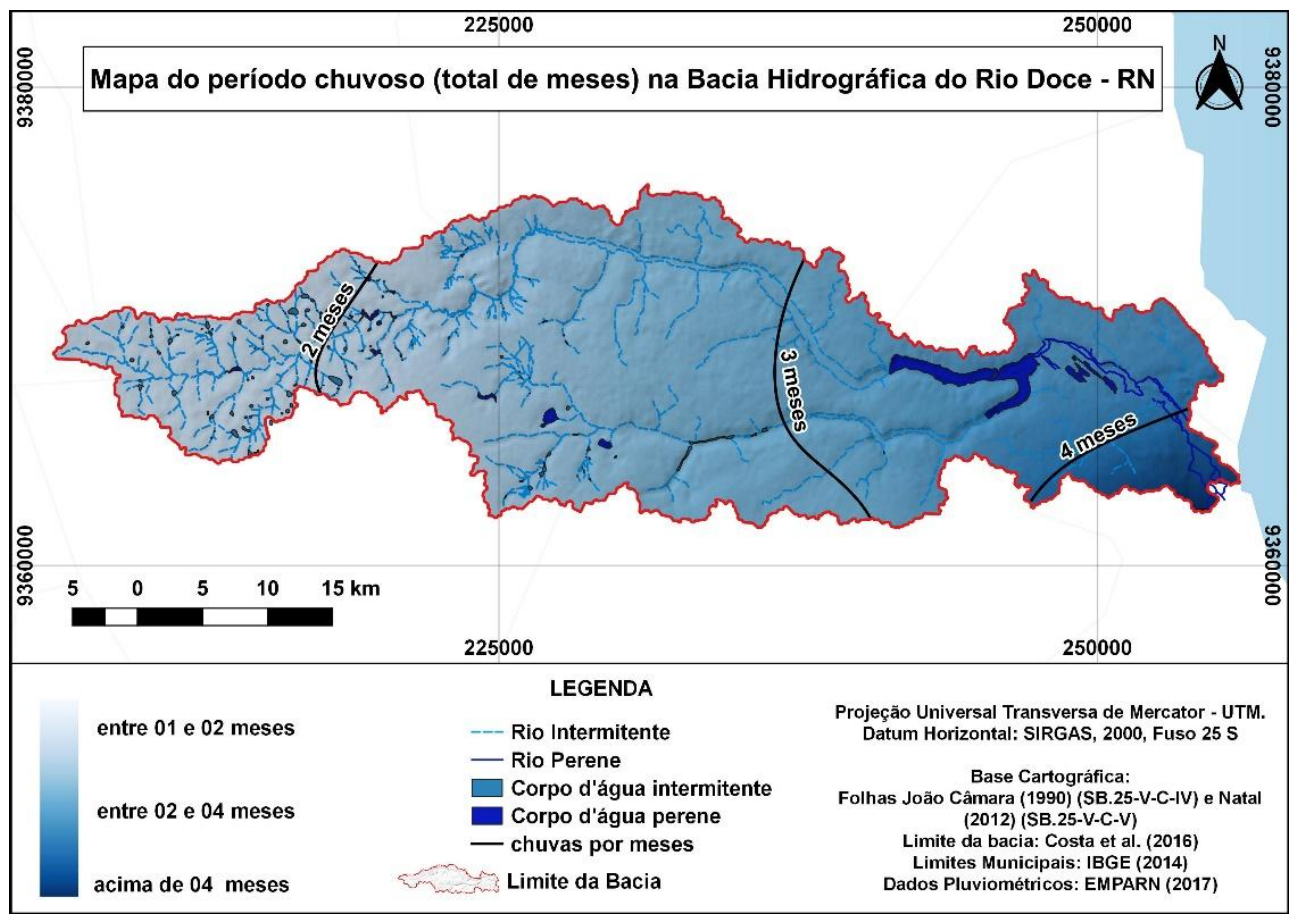

Figura 9 - Mapa da duração do período chuvoso, em número de meses, na BHRD-RN, a partir de dados obtidos na EMPARN, em 2017.

O município menos chuvoso foi Taipu, com média de 34 dias de chuvas por ano, equivalente a um pouco mais de 01 (um) mês; em seguida, aparecem Bento Fernandes (43 dias), Ielmo Marinho (55 dias) e Poço Branco (71 dias).

Por fim, comparando-se os dados obtidos na presente pesquisa com os de Castro (2000), observou-se uma diminuição na média de chuvas anuais, passando de 1109,65 mm para 1.036,10 mm. Significa uma diminuição, em valores percentuais, de 6,63\% (Tabela 3). Uma comparação entre os dados da pesquisa e os dados de Castro (2000) é mostrada na Tabela 3. As variações encontradas para maior valor estão em negrito.

É importante destacar que a série temporal trabalhada por Castro (2000) foi maior que do presente trabalho (1961 - 1990); ainda assim, a diferença entre os resultados obtidos em ambos os trabalhos pode ser considerada como pequena, menor que $7 \%$. 
Tabela 3 - Comparação entre os dados pluviométricos de Castro (2000) e os analisados na presente pesquisa, a partir dos dados obtidos na EMPARN, em 2017.

\begin{tabular}{|c|c|c|c|c|c|c|c|}
\hline Fonte & $\begin{array}{l}\text { Média } \\
\text { Anual }\end{array}$ & $\begin{array}{c}\text { Alto } \\
\text { Curso } \\
\text { (Precip. } \\
\text { máxima) }\end{array}$ & $\begin{array}{l}\text { Alto Curso } \\
\text { (Precip. } \\
\text { Mín.) }\end{array}$ & $\begin{array}{c}\text { Médio } \\
\text { Curso } \\
\text { (Precip. } \\
\text { Máx.) }\end{array}$ & $\begin{array}{c}\text { Médio } \\
\text { Curso } \\
\text { (Precip. } \\
\text { Mín.) }\end{array}$ & $\begin{array}{c}\text { Baixo } \\
\text { Curso } \\
\text { (Precip. } \\
\text { Máx.) }\end{array}$ & $\begin{array}{c}\text { Baixo } \\
\text { Curso } \\
\text { (Precip. } \\
\text { Mín.) } \\
\end{array}$ \\
\hline $\begin{array}{l}\text { Castro } \\
(2000)\end{array}$ & 1109,65 & 2432 & 306 & 2098 & 382 & 3511 & 530 \\
\hline $\begin{array}{l}\text { Resultad } \\
\text { os desta } \\
\text { pesquisa }\end{array}$ & 1036,10 & 1387,7 & 328,5 & 1772,4 & 609,1 & 2221,5 & 753 \\
\hline $\begin{array}{c}\text { Média po } \\
\text { bacia, } \\
\text { Castro }\end{array}$ & $\begin{array}{l}\text { trecho da } \\
\text { egundo } \\
\text { (2000) }\end{array}$ & \multicolumn{2}{|c|}{733,29} & \multicolumn{2}{|c|}{1032,65} & \multicolumn{2}{|c|}{1563} \\
\hline $\begin{array}{l}\text { Média por } \\
\text { bacia, nes }\end{array}$ & $\begin{array}{l}\text { trecho da } \\
\text { a pesquisa }\end{array}$ & \multicolumn{2}{|c|}{735,7} & \multicolumn{2}{|c|}{1199,2} & \multicolumn{2}{|c|}{1473,8} \\
\hline
\end{tabular}

Observou-se que, nos trechos da bacia, a diferença entre as maiores e menores precipitações anuais decresceram ao longo do tempo. Houve uma diminuição das médias atuais com maiores precipitações, mas, por outro lado, teve um aumento (dados em negrito) nos valores absolutos dos anos com menores precipitações anuais no período analisado.

\section{CONCLUSÕES}

De acordo com os dados analisados, a caracterização pluviométrica da Bacia Hidrográfica do Rio Doce - RN pode ser explicada, mediante a sua compartimentação, em 3 (três) recortes espaciais distintos: alto, médio e baixo curso ou, ainda, nas porções oeste, central e leste.

A porção oeste ou alto curso está localizada na unidade climática subúmido seco, conforme a classificação de Felipe (2006) e na unidade climática Úmido Seco, consoante a classificação da SEMARH (2005). A média anual das chuvas é de menos de 800 milímetros. A pluviosidade mensal é de menos de 2 meses, com exceção da área próxima ao município de Poço Branco, que apresentou 71 dias de chuvas no ano. A maior média anual no período foi de 1387,7 mm, em 2009, e a menor 328,5 mm, em 2010.

A porção centro-leste da bacia é considerada como unidade climática Sub-úmido para ambas as classificações. Na porção central da bacia, a média pluviométrica foi entre 1000 e 1200 milímetros anuais, com a concentração das chuvas ocorrendo durante o período de 3 meses. A maior precipitação ocorreu em $2004(1772,4)$ e a menor em 2010 (609,1 mm).

$\mathrm{Na}$ porção leste, a média pluviométrica foi maior que 1200 milímetros anuais, alcançando aproximadamente 1750 milímetros na foz da bacia. A maior média pluviométrica foi de 2221,5 mm, no ano de 2004, e a menor de $753 \mathrm{~mm}$, no ano de 2016.

Em relação à precipitação propriamente dita, a bacia, no geral, apresentou uma média anual pluviométrica, nos últimos 20 anos, de 1036,10 milímetros, considerado pela EMPARN como uma precipitação acumulada caracterizada como seco a normal, mas tendendo a um período mais seco. 
O número de dias com chuva na bacia foi de 81 por ano, o equivalente a quase 3 meses, sendo que o baixo curso apresenta mais meses chuvosos (06 meses) e o alto curso apresenta menos meses chuvosos (menos de 2 meses). Distribuindo os dias de chuva por mês, a média foi de 07 dias mensais, ao longo do ano. A média dos dias de chuva decresce na direção leste-oeste, ficando o baixo curso do rio com uma média de 11 dias de chuva por mês; o médio curso com 7 dias; e o alto curso com 4 dias de chuvas por mês, ao longo de um ano.

No decorrer do ano, há uma tendência de aumento das chuvas entre janeiro e março. Entre os meses de abril e julho, aumenta o número de dias chuvosos e o volume de água. Considera-se esse período como o mais chuvoso na bacia. Os dias com precipitação e o volume d'água diminuem a partir de julho. O período entre setembro e dezembro é considerado o mais seco na bacia, com média de 4 dias com chuvas (setembro), ocorrendo meses com apenas 2 dias com chuvas (outubro e novembro).

Os dados obtidos na pesquisa, quando comparados com os de Castro (2000), apresentam-se semelhantes, principalmente na média anual geral e nas médias gerais para o alto, médio e baixo curso do rio. No entanto, percebeu-se que houve uma diminuição nas maiores precipitações por período, comparando os dados anteriores e os atuais. Verificou-se aumento no valor das precipitações mínimas por período, quando comparado com os dados de Castro (2000). É importante destacar que o recorte temporal dos dados analisados por Castro foi maior que $o$ do presente trabalho, o que pode justificar as diferenças observadas.

\section{AGRADECIMENTOS}

Agradecimentos ao Programa Institucional de Capacitação do Pessoal Docente e Técnico Administrativo da UERN, à CAPES/UFRN e ao CNPq pela concessão de Bolsas para o desenvolvimento do trabalho.

\section{REFERÊNCIAS}

AMORIM, R.C.F.; RIBEIRO, A.; LEITE, C.C; LEAL, B.G.; SILVA, J.B.G. Avaliação do desempenho de dois métodos de espacialização da precipitação pluvial para o Estado de Alagoas. Acta Scientiarum Technology, v.30, n.1, p.87-91, 2008. Disponível http://periodicos.uem.br/ojs/index.php/ActaSciTechnol/article/view/3182

BAZARAA, A.S.; AHMED, S. Rainfall characterization in an arid area. Engineering Journal of Qatar University, v.4, 1991, p.35 - 50. Disponível em:http://quspace.qu.edu.qa/bitstream/handle/10576/7972/06-91-4-0004fulltext.pdf?sequence $=8$

CASTRO, V.L.L. Águas subterrâneas no curso inferior da bacia do rio Doce/RN: subsídios para um gerenciamento integrado. Tese (Doutorado em Geociências) USP, 2000.

COSTA, F.R; SOUZA, R.F.; SILVA, S.M.P. Análise comparativa de metodologias aplicadas à delimitação da bacia hidrográfica do rio Doce - RN. Sociedade e Natureza, 28(3), 429-442, 2016. http://dx.doi.org/10.1590/1982451320160308. 
CUNHA, E.M.S. Evolução atual do litoral de Natal - RN (Brasil) e suas aplicações a gestão integrada. Tese (Doutorado em Ciencial del Mar). Universitat de Barcelona. Barcelona, 2004.

EMBRAPA. Centro Nacional de Pesquisa de Solos. Sistema brasileiro de classificação de solos. Brasília: Embrapa Produção de Informação; Rio de Janeiro: Embrapa Solos, 2006.

EMPARN. Empresa de Pesquisa Agropecuária do Rio Grande do Norte. Chuvas observadas no RN. Disponível em: http://187.61.173.26/. Acesso em: 10 mar. 2017.

FELIPE, J.L.A.; CARVALHO, E.A.; ROCHA, A.P.B. Atlas Rio Grande do Norte: espaço geo-histórico e cultural. João Pessoa: Editora Grafset, 2006.

GARCEZ, L.N.; ALVAREZ, G.N. Hidrologia. 2.Ed. São Paulo: Editora Edgard Blucher, 1988.

IBGE. Instituto Brasileiro de Geografia e Estatística. Centro de documentação e disseminação de informações. Base de informações do censo demográfico 2010: resultados do universo por setor censitário. Rio de Janeiro: IBGE, 2014.

IDEMA - Instituto de Desenvolvimento Sustentável e Meio Ambiente. Banco de Dados Geográficos. Solos - RN, Escala: 1:100.000, 2012. CDROM

IGARN - Instituto de Gestão das Águas do Rio Grande do Norte. Programa Água Azul: bacia do rio Doce, 2009. Disponível em: http:/ http://adcon.rn.gov.br/ACERVO/IGARN/doc/DOC000000000028897.PDF. Acesso em: mar.2016.

KAYANO, M.T; ANDREOLI, R.V. Clima da Região Nordeste do Brasil. In: Cavalcanti, I.F.A.; FERREIRA, N.J.; SILVA, M.G.A.J.; DIAS, M.A.P.S. Tempo e clima no Brasil. São Paulo: Oficina de Textos, p.213-233, 2009.

KISAKA, M. O.; MUCHERU-MUNA, M.; NGETICH, F. K.; MUGENDI, J. N.; MUGENDI, D.; MAIURA, F. Rainfall variability, drought characterization, and efficacy of rainfall data reconstruction: case of eastern Kenya. Advances in Meteorology, vol. 2015, Article ID 380404, 16 pages, 2015. http://dx.doi.org/10.1155/2015/380404

LLASAT, M.C; RODRIGUEZ, R.: Towards a regionalization of extreme rainfall events in the Mediterranean Area. Friend'97, Regional Hydrology: Concepts and Models for Sustainable Water Resource Management. IAHS publ. 246, 215-222, Wallingford, United Kingdom, $1997 . \quad$ Disponível em: http://hydrologie.org/redbooks/a246/iahs_246_0215.pdf

LUCAS, E. W. M.; ASSIS, F.; SOUSA, S.; SILVA, F. D. S.; LUCIO, P. S. Modelagem hidrológica determinística e estocástica aplicada à região hidrográfica do Xingu - Pará. Revista Brasileira de Meteorologia, n. 3, p. 308322, 2009. http://dx.doi.org/10.1590/S0102-77862009000300005

MARCUZZO, F.F.N; ANDRADE, L.R.; MELO, D.C.R. Métodos de interpolação matemática no mapeamento de chuvas no estado do Mato Grosso. Revista Brasileira de Geografia Física, v.4, p.793-804, 2011. Disponível em: https://periodicos.ufpe.br/revistas/rbgfe/article/view/232714

MARTINS. A.P.; ROSA, R. Caracterização climática da bacia do rio Paranaíba a partir da rede de estações de superfície automática do INMET (2001-2011), 
utilizando ferramentas de geoprocessamento. Revista Geonorte, edição especial, v.2, n.5, pp.1303-1316, $2012 . \quad$ Disponível em: http://www.periodicos.ufam.edu.br/revista-geonorte/article/view/2581

PAULHUS, J.L.H.; KOHLER, M.A. Interpolation of missing precipitation records. Monthly Weather Review, v. 80, n. 8, p. 129-133. 1952. https://doi.org/10.1175/1520-0493(1952)080\%3C0129:IOMPR\%3E2.0.CO;2

PEREIRA, E.R.R. Índices pluviométricos na análise da intensidade e variabilidade regional das chuvas no Nordeste do Brasil. Tese (Doutorado em Meteorologia) Universidade Federal de Campina Grande, Centro de Tecnologia e Recursos Naturais, 2014.

RAO. V.B., LIMA, M., FRANCHITO, S.H. Seazonal and Interannual Variations of Rainfall over Eastern Northeast Brazil. Journal of Climate, v.6, pp. 1754-1763, 1993.https://doi.org/10.1175/1520-

0442(1993)006\%3C1754:SAIVOR\%3E2.0.CO;2

SANTOS, C.A.; SERRÃO, E.A.O; GONÇALVES, L.J.M.; WNAZELER, R.T.S.; LIMA, A.M.M. Zoneamento da distribuição da precipitação pluviométrica na bacia hidrográfica do rio Tapajós. Enciclopédia Biosfera. Goiânia, v.10, n.18, p.3092 3106, $2014 . \quad$ Disponível em: www.conhecer.org.br/enciclop/2014a/AGRARIAS/zoneamento.pdf

SANTOS, J. Lista dos Códigos EPSG mais utilizados no Brasil, 2013.Disponível em: http://www.processamentodigital.com.br/2013/07/27/lista-dos-codigosepsg-mais-utilizados-no-brasil/. Acesso em: 10 mar. 2017.

Secretaria de Meio Ambiente e Recursos Hídricos - SEMARH/RN. Bacia do Rio Doce, $2000 . \quad$ Disponível em: http://servicos.searh.rn.gov.br/semarh/sistemadeinformacoes/consulta/cBaciaD etalhe. asp?CodigoEstadual=07. Acesso em: abr. 2016.

Programa estadual de desenvolvimento sustentável e convivência com o semi-árido potiguar. Relatório de Avaliação do Programa. Natal - RN, 2005.

SILVA, N.S; RIBEIRO, C.A.A.S; BARROSO, W.R.; RIBEIRO, P.E.A.; SOARES, V.P.; SILVA, E. Sistema de otto-codificação modificado para endereçamento de redes hidrográficas. Revista Árvore, Viçosa - MG, v.32, n.5, p.891-897, 2008. http://dx.doi.org/10.1590/S0100-67622008000500014

SIMIONI, J. P. D.; ROVANI, F.M.R.; IENSSE, A.C.; WOLLMANN, A. Caracterização da precipitação pluviométrica na bacia hidrográfica do rio Ibicuí, RS. Revista do Departamento de Geografia, São Paulo, v. 28, p. 112-133, feb. 2015. ISSN 2236-2878. Disponível em: https://www.revistas.usp.br/rdg/article/view/90008/92798

WANDERLEY, H.S.; AMORIM, R.F.C.; CARVALHO, F.O. Interpolação espacial de dados médios mensais pluviométricos com redes neurais artificiais. Revista Brasileira de Meteorologia, v.29, n.3, pp. 389-396, 2014. http://dx.doi.org/10.1590/0102-778620130639. 